\title{
TOLERÂNCIA DE MAMONA (Ricinus communis) A HERBICIDAS UTILIZADOS NA CULTURA DA CANA-DE-AÇÚCAR
}

\author{
Fabricio Simone Zera ${ }^{1}$ \\ Carlos Alberto Mathias Azania ${ }^{2}$ \\ Ana Regina Schiavetto ${ }^{3}$ \\ Cassia Morilha Lorenzato ${ }^{4}$ \\ Gilberto Braz Freitas ${ }^{5}$ \\ Andrea Aparecida de Padua Mathias Azania ${ }^{6}$
}

\begin{abstract}
RESUMO: O desenvolvimento de Ricinus communis é favorecido em canaviais colhidos sem a prévia despalha a fogo. Porém, o manejo não é satisfatório na maioria dos canaviais, mesmo quando se utiliza do manejo químico. A tolerância pode estar na origem das plantas, que podem ser oriundas de plantas cultivadas ou silvestres. Nesse contexto, objetivou-se avaliar a tolerância de plantas de Ricinus communis silvestres e cultivadas a herbicidas recomendados ao manejo da cana-de-açúcar. As cultivares utilizadas no experimento foram IAC 80, IAC 2028, IAC Guarani e silvestre, e os herbicidas sulfentrazone ( $\left.800 \mathrm{~g} \mathrm{ha}^{-1}\right)$, imazapic (147 $\mathrm{g}$ $\left.\mathrm{ha}^{-1}\right)$, isoxaflutole $\left(112 \mathrm{~g} \mathrm{ha}^{-1}\right)$, clomazone $\left(1100 \mathrm{~g} \mathrm{ha}^{-1}\right)$ e ametryn $\left(1460 \mathrm{~g} \mathrm{ha}^{-1}\right)+$ trifloxysulfuron-sodium (37 $\mathrm{g} \mathrm{ha}^{-1}$ ) e uma testemunha. O delineamento utilizado foi em blocos casualizados com 24 tratamentos distribuídos em esquema de parcelas subdivididas. Os herbicidas e testemunha (6) foram alocados nas parcelas e as cultivares de mamona (4) nas subparcelas. As parcelas $\left(36 \mathrm{~m}^{2}\right)$ foram constituídas por quatro subparcelas de seis linhas de $3 \mathrm{~m}$ de comprimento e espaçadas de $0,5 \mathrm{~m}$, totalizando $9 \mathrm{~m}^{2}$ cada. Nas subparcelas semeou-se em cada linha as sementes, que proporcionaram média de 5 plantas por metro, sendo as 4 linhas centrais consideradas úteis às avaliações. Os herbicidas foram aplicados em pré-emergência das espécies, após semeadura nas sub-parcelas. Foram avaliados visualmente os sintomas de intoxicação na parte aérea das plantas aos 15 e 30 DAA; altura (cm), número e massa seca das plantas aos 30 DAA. As cultivares de Ricinus communis foram suscetíveis aos herbicidas sulfentrazone, imazapic e isoxaflutole e tolerantes aos demais herbicidas, enquanto que o material silvestre foi mais suscetível a sulfentrazone, devido à redução na altura e massa seca.
\end{abstract}

Palavras-chave: Controle químico. Planta daninha. Seletividade.

\section{Ricinus communis TOLERANCE TO HERBICIDES USED IN SUGARCANE CROP}

SUMMARY: The development of Ricinus communis is favored in sugarcane harvested without prior burning. However, management is not satisfactory in most sugar cane plantations, even when using the chemical management. The tolerance may be the plants origin, which can be derived from cultivated or wild plant. This experiment aimed to evaluate the tolerance of Ricinus communis plants wild and farmed to the herbicides recommended for sugarcane management. The cultivars used in the experiment were IAC 80, IAC 2028, IAC Guarani and wild and the herbicides sulfentrazone $\left(800 \mathrm{~g} \mathrm{ha}^{-1}\right)$, imazapic $\left(147 \mathrm{~g} \mathrm{ha}^{-1}\right)$, isoxaflutole $\left(112 \mathrm{~g} \mathrm{ha}^{-1}\right)$, clomazone $\left(1100 \mathrm{~g} \mathrm{ha}^{-1}\right)$ and ametryn $\left(1460 \mathrm{~g} \mathrm{ha}^{-1}\right)$ trifloxysulfuron-sodium $\left(37 \mathrm{~g} \mathrm{ha}^{-1}\right)$ and a control. The experimental design was a randomized block with 24 treatments arranged in split plots. Herbicides and control

\footnotetext{
1 Engenheiro Agrônomo, Pós-Graduando do Curso de Agricultura Tropical e Subtropical do Instituto Agronômico, Centro de Cana. Rod. Pref. Antonio Duarte Nogueira, km 321, CEP 14032-800, Ribeirão Preto, SP

2 Engenheiro Agrônomo, Pesq. Científico do Centro de Cana do Instituto Agronômico

${ }^{3}$ Engenheira Agrônoma, Mestranda em Genética e Melhoramento de Plantas, FCAV, Jaboticabal, SP

${ }^{4}$ Engenheira Agrônoma, Centro Univ. Moura Lacerda, Estagiária de Treinamento Técnico do Centro de Cana

${ }^{5}$ Engenheiro Agrônomo, Mestrando do Curso de Agricultura Tropical e Subtropical do Instituto Agronômico

${ }^{6}$ Bióloga, Pesquisadora Científica Voluntária, Instituto Agronômico, Centro de Cana, Ribeirão Preto, SP.
} 
(6) were allocated to plots and the Ricinus communis cultivars (4) the subplots. The plots $\left(36 \mathrm{~m}^{2}\right)$ consisted of four plots of six rows of $3 \mathrm{~m}$ long and spaced $0.5 \mathrm{~m}$, a total of $9 \mathrm{~m}^{2}$ each. In subplot was sown the seeds in each row, which provided an average of 5 plants per meter, and the four central lines considered useful for the evaluations. Herbicides were applied pre-emergence of species, after sowing the sub-plots. The symptoms of intoxication were visually assessed in aerial part of plants at 15 and 30 DAA; height $(\mathrm{cm})$, number and plant dry weight at 30 DAA. Ricinus communis cultivars were susceptible to sulfentrazone, isoxaflutole and imazapic and tolerant to other herbicides, while wild material was more susceptible to sulfentrazone, due to the reduction in height and dry weight.

Key words: Chemical control. Selectivity. Weed.

\section{INTRODUÇÃO}

Nos últimos anos o setor sucroalcooleiro tem expandido a colheita da cana sem a prévia despalha a fogo, atendendo à atual legislação sobre o fim da queima nos canaviais. Entretanto, a alteração sobre o sistema de colheita proporcionou mudanças na intensidade de luz, na temperatura e na umidade do solo devido à presença da palha, e conseqüentemente alterações na flora daninha. Essas condições, segundo Martins et al. (1999), possibilitaram o aumento populacional de espécies anteriormente de pouca expressão nos canaviais, sendo um exemplo Ricinus communis, popularmente conhecida como mamona.

A mamona (Ricinus communis L.) é uma planta de origem tropical, pertencente à família Euphorbiaceae ( FERREIRA et al., 2009), que apresenta hábito arbustivo, com diversas colorações de caule, folhas e frutos tipo racemos, os quais geralmente possuem espinhos e suas sementes apresentam diferentes tamanhos, formatos e grande variabilidade de coloração ( LIMA et al., 2007). A espécie vem se caracterizando como planta daninha, especialmente nos canaviais devido à sua resistência ao estresse hídrico, ao crescimento rápido, que causa sombreamento na cultura, e à eficiente competição por nutrientes (THEISEN; ANDRES, 2007 ). No campo, os frutos da espécie eclodem e lançam as sementes a longas distâncias, colaborando com sua disseminação. Outro agravante é que à medida que a planta se desenvolve, o caule torna-se lignificado e rígido, causando acidentes de trabalho, especialmente para os operadores de máquinas (RAMIA et al. 2009).

De acordo com dados do MAPA: Ministério da Agricultura, Pecuária e Abastecimento (2010), verificou-se o herbicida trifluralin como o único produto seletivo registrado para aplicação em pré-emergência da mamona. Na literatura, são encontrados herbicidas seletivos a Ricinus communis em pré-emergência, como alachlor, diuron, linuron, EPTC, simazine, trifluralin (WEISS, 1983; GELMINI, 1985); fluazifop-p-butílico, sethoxydim, haloxyfopmethyl, clethodim+fenoxaprop-p-ethyl, quizalofop-p-ethyl, clethodim, propaquizafop, tetraloxydim e butroxydim (MARTINS et al., 2004); clomazone e clomazone+trifluralin (MACIEL et al., 2007). 
O conhecimento da ação dos herbicidas que controlam plantas não comuns à flora dos canaviais, a exemplo da mamona, é de grande importância para o correto manejo do canavial. $\mathrm{Na}$ literatura, a mamona é referenciada em cultivos para produção de biodiesel, sendo apresentada como cultura e não como planta daninha. Porém, em cana-de-açúcar, a espécie tem demonstrado capacidade de competição com a cultura, causando prejuízos. Desta forma, o objetivo do trabalho foi avaliar a tolerância de plantas de Ricinus communis silvestres e cultivadas a herbicidas recomendados ao manejo da cana-de-açúcar.

\section{MATERIAL E MÉTODOS}

O experimento foi realizado entre os meses de fevereiro a abril/09 em Latossolo Vermelho Escuro, classe textural argilosa (509 $\mathrm{g} \mathrm{kg}^{-1}$ de argila, $343 \mathrm{~g} \mathrm{~kg}^{-1}$ de silte e $148 \mathrm{~g} \mathrm{~kg}^{-1}$ de areia na camada arável) e com $24 \mathrm{~g} \mathrm{dm}^{-3}$ de matéria orgânica; 5,0 de $\mathrm{pH}\left(\mathrm{CaCl}_{2}\right) ; 57 \mathrm{mg}$ $\mathrm{dm}^{-3}$ de P; 2,6 $\mathrm{mmol}_{\mathrm{c}} \mathrm{dm}^{-3}$ de K; $29 \mathrm{mmol}_{\mathrm{c}} \mathrm{dm}^{-3}$ de Ca; $8 \mathrm{mmol}_{\mathrm{c}} \mathrm{dm}^{-3} \mathrm{de} \mathrm{Mg}$; CTC de 79,6 e $\mathrm{V}$ de $49,7 \%$ como atributos químicos. O solo foi devidamente adubado para atender as condições da cultura da cana-de-açúcar, para simular as mesmas condições que as plantas de Ricinus communis encontrariam nos canaviais.

As sementes de cultivares de Ricinus communis utilizadas foram a IAC 80, a IAC Guarani e a IAC 2826, obtidas no Centro de Grãos e Fibras do Instituto Agronômico (IAC) e as sementes de material silvestre foram coletadas em terrenos baldios e canaviais. Na coleta padronizou-se a escolha de frutos maduros próximos a senescência natural, evitando-se assim as sementes não maduras. As sementes foram selecionadas, evitando-se aquelas de cor branca, quebradas, predadas, deformadas e chochas, sendo então colocadas em recipientes de plástico e armazenadas em geladeira até o momento da semeadura.

Antes da semeadura, para caracterizar a qualidade dos lotes, procedeu-se ao teste de germinação utilizando-se do método de Edmond; Drapala (1958) para os cálculos da porcentagem de germinação, do índice de velocidade de emergência (IVE) e da velocidade de emergência (VE). Para o teste de viabilidade, as sementes foram colocadas em água na temperatura ambiente durante 12 horas para romper o tegumento e posteriormente foram cortadas longitudinalmente, acondicionadas em recipientes de vidro âmbar acrescidos de solução de cloreto de 2,3,5 trifeniltetrazolio a $0,1 \%$. Os recipientes foram mantidos no escuro durante 8 horas, posteriormente realizou-se a contagem do número de sementes com embriões coloridos de rósea. Avaliou-se ainda a massa de 100 sementes por espécie ou cultivar, para completar a caracterização dos lotes. Para cada cultivar pesou-se 4 repetições com 100 sementes para compor a média da massa. 
Os herbicidas utilizados foram sulfentrazone (800 $\left.\mathrm{g} \mathrm{ha}^{-1}\right)$, imazapic (147 $\left.\mathrm{g} \mathrm{ha}^{-1}\right)$, isoxaflutole $\left(112 \mathrm{~g} \mathrm{ha}^{-1}\right)$, clomazone $\left(1100 \mathrm{~g} \mathrm{ha}^{-1}\right)$ e ametryn $\left(1460 \mathrm{~g} \mathrm{ha}^{-1}\right)+$ trifloxysulfuronsodium $\left(37 \mathrm{~g} \mathrm{ha}^{-1}\right)$ e um tratamento testemunha.

O delineamento utilizado foi em blocos casualizados com 24 tratamentos distribuídos em esquema de parcelas subdivididas. Os herbicidas e testemunha (6) foram alocados nas parcelas e as cultivares de mamona (4) nas subparcelas. As parcelas $\left(36 \mathrm{~m}^{2}\right)$ foram constituídas por quatro subparcelas de seis linhas de $3 \mathrm{~m}$ de comprimento e espaçadas de 0,5 $\mathrm{m}$, totalizando $9 \mathrm{~m}^{2}$ cada. Nas subparcelas semeou-se em cada linha as sementes, que proporcionaram média de 5 plantas por metro, sendo as 4 linhas centrais consideradas úteis às avaliações.

A aplicação dos herbicidas foi realizada logo após a semeadura, na condição de préemergência das plantas daninhas, em 07/03/2009, com pulverizador costal pressurizado, com barra munida com quatro pontas de jato leque (TT110/02), espaçadas de 0,50 m, trabalhando com pressão constante de $2,1 \mathrm{kgf} \mathrm{cm}^{-2}$, proporcionando o correspondente a $250 \mathrm{~L} \mathrm{ha}^{-1} \mathrm{de}$ calda. No momento da aplicação registrou-se temperatura de $32^{\circ} \mathrm{C}$, umidade relativa de $59 \%$, vento em rajadas de $0,8 \mathrm{~km} \mathrm{~h}^{-1}$ e ausência de nebulosidade.

Os sintomas de fitotoxicidade foram avaliados visualmente na parte aérea das plantas, aos 15 e 30 dias após a aplicação (DAA). A atribuição das notas sobre os sintomas visuais observados foram de acordo com escala percentual, onde $0 \%$ corresponde à ausência de injúrias e $100 \%$ à morte das plantas.

Aos 30 DAA, avaliou-se também na área útil das sub-parcelas, a altura das plantas, medindo em centímetro cada planta desde o nível do solo até a última folha; o número de plantas, obtido contando-se todas as plantas; e a massa seca da parte aérea, que foi obtida cortando-se as plantas rente ao solo com posterior secagem em estufa de circulação forçada de ar a temperatura de $70^{\circ} \mathrm{C}$ até peso constante.

As variáveis avaliadas foram submetidas à análise de variância pelo teste $\mathrm{F}$. Posteriormente, na comparação das médias dos tratamentos, utilizou-se o teste de Tukey a 5\% de probabilidade. Os dados de altura e massa seca foram transformados em raiz de $\mathrm{x}+0,5$.

\section{RESULTADOS E DISCUSSÃO}

As sementes das cultivares de mamona apresentaram germinação superior à das sementes silvestres, característica apresentada pelas plantas melhoradas devido à maturação ser uniforme. Entretanto quanto à viabilidade, tanto as cultivares quanto as sementes das plantas silvestres apresentaram valores superiores a 98\%. A VE e o IVE também não foram 
discrepantes entre os genótipos. A massa das sementes, em ordem decrescente, foi maior para a cultivar IAC Guarani, IAC 2028, IAC 80 e por último as sementes silvestres (Tabela 1).

Tabela 1. Germinação, índice de velocidade de emergência (IVE), velocidade de emergência (VE), viabilidade e massa das sementes de cada lote utilizado no experimento. IAC, 2010.

\begin{tabular}{|c|c|c|c|c|c|}
\hline & Germinação & IVE & VE & Viabilidade & $\begin{array}{c}\text { Massa } \\
100 \text { sementes }\end{array}$ \\
\hline Espécies & $(\%)$ & & & $(\%)$ & (g) \\
\hline $\begin{array}{c}\text { R. communis } \\
\text { (silvestre) }\end{array}$ & 47 & 3,20 & 16,78 & 98 & 12,4 \\
\hline $\begin{array}{l}\text { R. communis } \\
\text { (IAC Guarani) }\end{array}$ & 84 & 4,63 & 18,15 & 100 & 53,5 \\
\hline $\begin{array}{l}R . \text { communis } \\
\text { (IAC 80) }\end{array}$ & 89 & 6,08 & 15,38 & 100 & 29,2 \\
\hline $\begin{array}{l}\text { R. communis } \\
\text { (IAC 2028) }\end{array}$ & 68 & 3,87 & 18,45 & 99 & 39,4 \\
\hline
\end{tabular}

O material silvestre de $R$. communis foi suscetível ao tratamento com sulfentrazone desde os 15 DAA, ocasião em que se observou no estádio cotiledonar manchas necróticas nas folhas, atribuindo-se nota de $98 \%$ aos sintomas de fitotoxicidade considerados como severos. Aos 30 DAA ainda se observou manchas necróticas, atribuindo-se notas de 96\% (Figura 1). Os sintomas de fitotoxicidade nas folhas das plantas de $R$. communis tratadas com sulfentrazone são devido à inibição da enzima Protox, que possui efeitos sobre a síntese de lipídeos e a constituição da parede celular, causando morte do tecido e manchas necróticas (ZOBIOLE et al., 2007). 


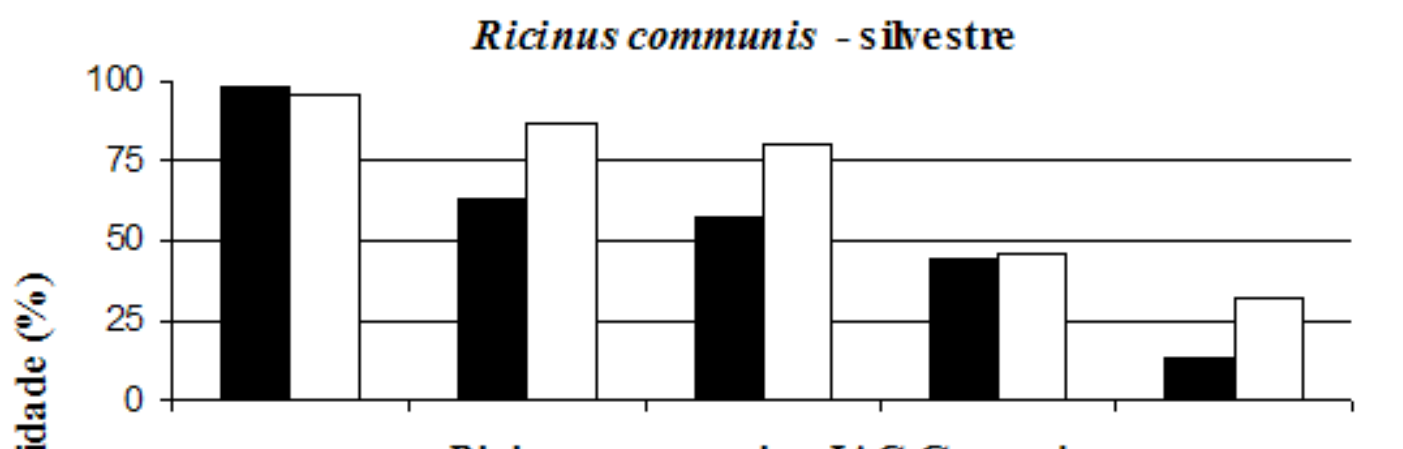

Ricinus communis - IAC Guarani

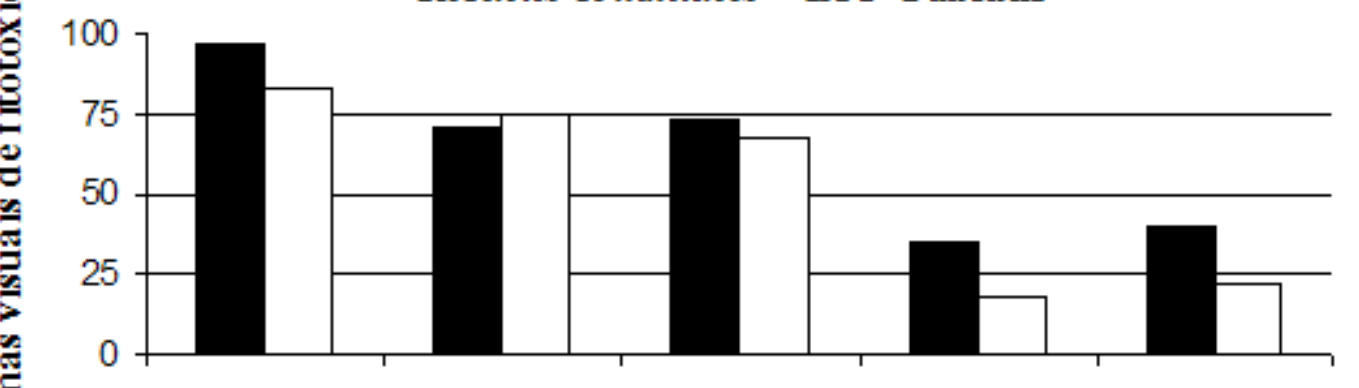

Ricinus communis - IAC 80
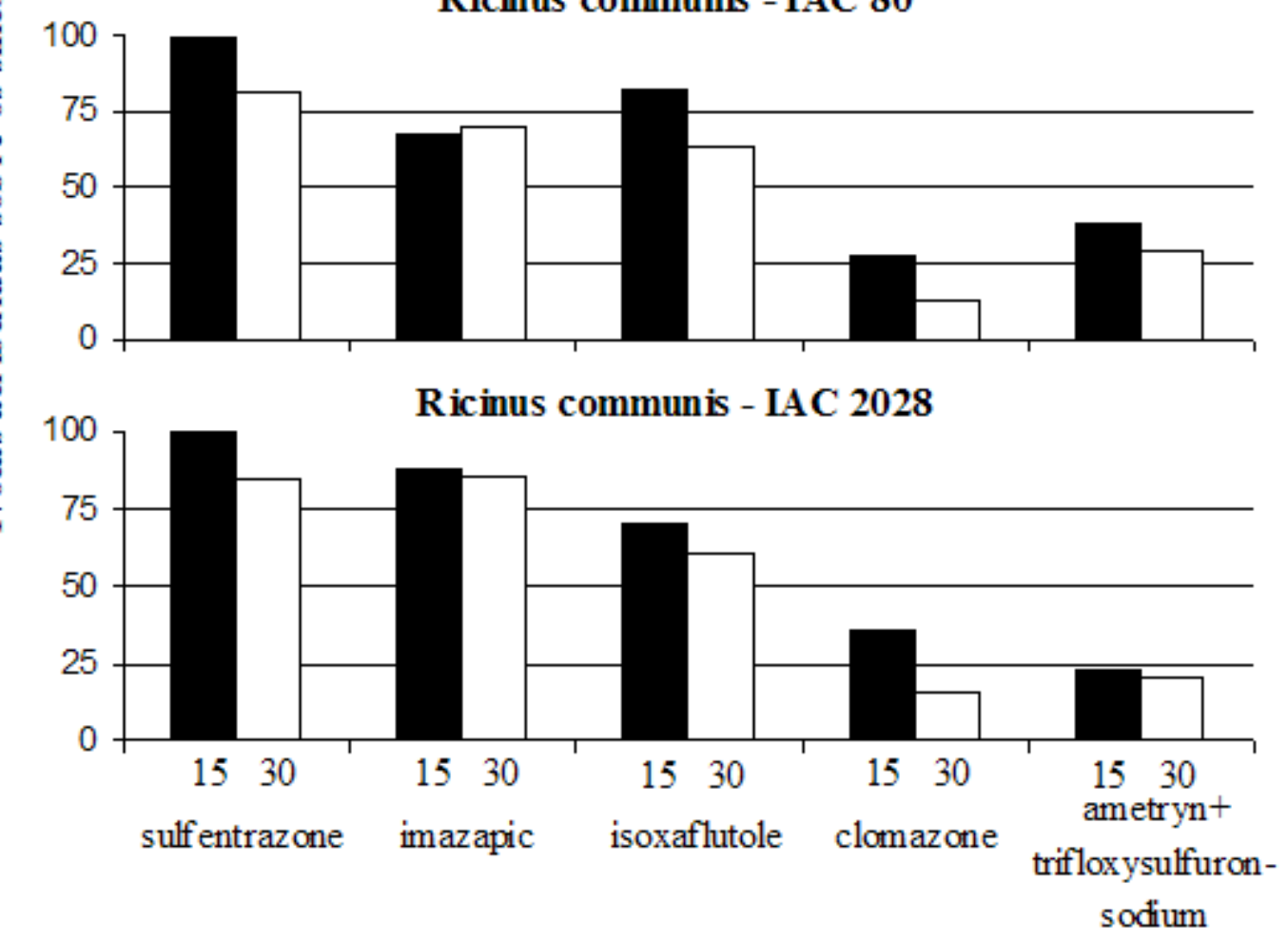

Figura 1. Fitotoxicidade dos herbicidas sulfentrazone, imazapic, isoxaflutole, clomazone e ametryn + trifloxysulfuron-sodium, aplicados em pré-emergência nos diferentes genótipos de R. communis aos 15 e 30 dias após aplicação. Média de quatro repetições. IAC, 2010.

As plantas do material silvestre também foram suscetíveis ao tratamento com imazapic. Os sintomas de fitotoxicidade avaliados aos 15 e 30 DAA foram de 63 e 89\%, respectivamente. Não foi observado morte nas plantas tratadas com imazapic, mas desde o estádio cotiledonar as folhas apresentaram necrose e enfezamento das plantas, sendo esses sintomas característicos dos herbicidas com mecanismos de ação de inibidores de ALS. Os 
sintomas causados pelos herbicidas pertencente a esse mecanismo de ação, de acordo com Merotto Júnior et al. (2000), começam com a clorose das folhas jovens e surgimento posterior de coloração avermelhada nas nervuras da face abaxial e posterior evolução para necrose das folhas.

Verificou-se que as plantas do material silvestre foram moderadamente suscetíveis aos herbicidas isoxaflutole, clomazone e ametryn+trifloxysulfuron-sodium, que tiveram atribuídas notas de 57 e 80\%; 44 e 46\%; 13 e 32\% aos 15 e 30 DAA, respectivamente. Esses herbicidas não proporcionaram a morte das plantas, que apresentaram manchas amarelas e brancas.

Nas plantas das cultivares IAC Guarani, IAC 80 e IAC 2028 de $R$. communis foram observados os sintomas de fitotoxicidade entre os herbicidas, podendo classificá-los na seguinte ordem decrescente de fitotoxicidade: sulfentrazone, imazapic, isoxaflutole, clomazone e ametryn+trifloxysulfuron-sodium. Os sintomas observados na parte aérea das plantas também foram similares aqueles constatados no material silvestre.

Em literatura foram encontradas referências sobre sintomas de fitotoxicidade similares aos observados em campo. Beltrão et al. (2004), constataram injúrias leves às cultivares BRS 149 Nordestina e BRS 188 Paraguaçu ao aplicarem diuron $\left(2,4 \mathrm{~kg} \mathrm{ha}^{-1}\right)$ e pendimethalin $(1,5$ $\mathrm{kg} \mathrm{ha}^{-1}$ ). Theisen et al. (2006) ao estudarem R. communis, cv. AL Guarani, observaram que atrazine não foi seletivo às plantas causando necrose foliar e redução no crescimento das plantas em estádios superiores a cinco folhas e que clomazone causou leves injúrias. Maciel et al. (2007) observaram injúrias de efeitos leves, quando aplicaram o herbicida clomazone (1000 g i.a ha ${ }^{-1}$ ), para as cultivares de mamona Íris e AL Guarany 2002, e Ferreira et al. (2009) verificaram que independente dos estádios de desenvolvimento (duas folhas, duas folhas verdadeiras, duas folhas expandidas e quatro folhas), trifloxysulfuron-sodium foi fitotóxico para a cultivar BRS Nordestina mesmo na menor dosagem utilizada $\left(5,0 \mathrm{~g} \mathrm{ha}^{-1}\right)$.

Analisando cada material de mamona quanto ao número de plantas dentro dos tratamentos herbicidas (Tabela 2), verificou-se que o sulfentrazone foi o mais prejudicial ao material silvestre, enquanto para IAC Guarani, IAC 80 e IAC 2028 foram sulfentrazone e o imazapic. 
Tabela 2. Efeito da interação entre herbicidas e espécies de $R$. communis sobre o número de plantas de mamonas aos 30 dias após aplicação do produto. IAC, 2010.

\begin{tabular}{|c|c|c|c|c|c|c|c|}
\hline \multirow{2}{*}{$\begin{array}{l}\text { Espécies } \\
\text { (A) }\end{array}$} & \multicolumn{6}{|c|}{ Herbicidas (B) } & \multirow[b]{2}{*}{$\mathbf{F}$} \\
\hline & Testemunha & $\begin{array}{c}\text { sulfentrazone } \\
\left(0,8 \mathrm{~kg} \mathrm{ha}^{-1}\right)\end{array}$ & $\begin{array}{c}\text { imazapic } \\
\left(0,147 \mathrm{~kg} \mathrm{ha}^{-1}\right)\end{array}$ & $\begin{array}{c}\text { isoxaflutole } \\
\left(0,1125 \mathrm{~kg} \mathrm{ha}^{-1}\right)\end{array}$ & $\begin{array}{l}\text { clomazone } \\
\left(1,1 \mathrm{~kg} \mathrm{ha}^{-1}\right)\end{array}$ & $\begin{array}{c}\text { ametryn+tss } \\
\left(1463+0,037 \mathrm{~kg} \mathrm{ha}^{-1}\right)\end{array}$ & \\
\hline Silvestre & $39,75 \mathrm{Aa}$ & $3,75 \mathrm{Cb}$ & $20,75 \mathrm{BCab}$ & $27,00 \mathrm{ABb}$ & $40,50 \mathrm{Ab}$ & $38,50 \mathrm{Aa}$ & $12,04 * *$ \\
\hline $\begin{array}{l}\text { IAC } \\
\text { Guarani }\end{array}$ & $49,25 \mathrm{Aa}$ & $10,25 \mathrm{Bab}$ & $20,25 \mathrm{Bab}$ & $44,00 \mathrm{Aa}$ & $52,00 \mathrm{Aab}$ & $43,50 \mathrm{Aa}$ & $16,82 * *$ \\
\hline IAC 80 & $41,25 \mathrm{ABa}$ & $19,75 \mathrm{Ca}$ & $29,50 \mathrm{BCa}$ & $52,75 \mathrm{Aa}$ & 44,25 ABab & $30,50 \mathrm{BCa}$ & $8,20 * *$ \\
\hline IAC 2028 & $49,25 \mathrm{Aa}$ & $12,50 \mathrm{Bab}$ & $12,00 \mathrm{Bb}$ & $53,00 \mathrm{Aa}$ & $56,00 \mathrm{Aa}$ & $41,25 \mathrm{Aa}$ & $23,14 * *$ \\
\hline $\mathbf{F}$ & $1,70^{\mathrm{ns}}$ & $2,86^{*}$ & $3,35^{*}$ & $7,76^{* *}$ & $3,20^{*}$ & $2,11^{\mathrm{ns}}$ & \\
\hline
\end{tabular}

tss (trifloxysulfuron-sodium); * (significativo a 5\% de probabilidade pelo teste $\mathrm{F}$ ); ** (significativo a 1\% de probabilidade pelo teste F); ns (não significativo); Letras maiúsculas compara-se na linha e minúsculas na coluna.

Aos 30 DAA, a altura das plantas foi reduzida quando foram aplicados imazapic, sulfentrazone e isoxaflutole (Tabela 3). Em comparação com a testemunha, sulfentrazone e imazapic reduziram a massa seca da parte aérea da mamona. As cultivares melhoradas pelo IAC tiveram altura e massa seca da parte aérea superiores à do material silvestre. Ramia et al. (2009) verificaram maiores injúrias, menor altura e massa seca das plantas silvestres de mamona quando os herbicidas foram aplicados na fase de sementeira e pós-emergência inicial. Entretanto, ametryn+trifloxysulfun-sodium aplicados na pós-emergência tardia e 2,4D em pré-emergência prejudicaram menos as plantas. 
Tabela 3. Altura e Massa seca das plantas de $R$. communis aos 30 dias após aplicação de herbicidas em pré-emergência. IAC, 2010.

\begin{tabular}{|c|c|c|c|c|}
\hline \multirow{2}{*}{ Causas de variação } & \multicolumn{2}{|c|}{$\begin{array}{l}\text { Altura } \\
(\mathbf{c m})\end{array}$} & \multicolumn{2}{|c|}{$\begin{array}{c}\text { Massa Seca } \\
\text { (g) }\end{array}$} \\
\hline & orig. & transf. & orig. & transf. \\
\hline \multicolumn{5}{|l|}{ Herbicidas (A) } \\
\hline Testemunha & 55,49 & $7,41 \mathrm{a}$ & 37,60 & $6,03 \mathrm{ab}$ \\
\hline sulfentrazone $\left(0,8 \mathrm{~kg} \mathrm{ha}^{-1}\right)$ & 22,20 & $4,41 \mathrm{~b}$ & 7,09 & $2,20 \mathrm{c}$ \\
\hline imazapic $\left(0,147 \mathrm{~kg} \mathrm{ha}^{-1}\right)$ & 18,50 & $4,17 \mathrm{~b}$ & 6,51 & $2,39 \mathrm{c}$ \\
\hline isoxaflutole $\left(0,1125 \mathrm{~kg} \mathrm{ha}^{-1}\right)$ & 30,63 & $5,31 \mathrm{~b}$ & 22,36 & $4,19 \mathrm{bc}$ \\
\hline clomazone $\left(1,1 \mathrm{~kg} \mathrm{ha}^{-1}\right)$ & 60,24 & $7,61 \mathrm{a}$ & 53,74 & $7,04 \mathrm{a}$ \\
\hline ametryn+tss $\left(1463+0,037 \mathrm{~kg} \mathrm{ha}^{-1}\right)$ & 48,53 & $6,91 \mathrm{a}$ & 40,94 & $6,24 \mathrm{ab}$ \\
\hline$F$ & & $22,26^{* *}$ & & $19,67 * *$ \\
\hline $\mathrm{CV}(\%)$ & & 21,77 & & 18,38 \\
\hline Dms & & 1,49 & & 2,15 \\
\hline \multicolumn{5}{|l|}{ Espécies (B) } \\
\hline Silvestre & 29,06 & $4,94 \mathrm{~b}$ & 15,79 & $3,38 \mathrm{c}$ \\
\hline IAC Guarani & 40,34 & $6,14 \mathrm{a}$ & 27,51 & $4,69 \mathrm{~b}$ \\
\hline IAC 80 & 46,13 & $6,61 \mathrm{a}$ & 36,48 & $5,63 \mathrm{a}$ \\
\hline IAC 2028 & 41,52 & $6,19 \mathrm{a}$ & 32,37 & $5,03 \mathrm{ab}$ \\
\hline $\mathrm{F}$ & & $24,29 * *$ & & $29,33 * *$ \\
\hline $\mathrm{CV}(\%)$ & & 11,93 & & 18,38 \\
\hline Dms & & 0,55 & & 0,65 \\
\hline$A \times B$ & & $1,21^{\mathrm{ns}}$ & & $1,16^{\mathrm{ns}}$ \\
\hline
\end{tabular}

tss (trifloxysulfuron-sodium); orig. - dados originais; transf. - dados transformados raiz $\mathrm{x}+0,5 ; * *$ (significativo a $1 \%$ de probabilidade pelo teste $\mathrm{F}$ ); ns (não significativo); CV (coeficiente de variação); dms (diferença mínima significativa).

\section{CONCLUSÃO}

As cultivares de Ricinus communis foram suscetíveis aos herbicidas sulfentrazone, imazapic e isoxaflutole e tolerantes aos demais herbicidas, enquanto que o material silvestre foi mais suscetível a sulfentrazone, devido à redução na altura e massa seca.

\section{REFERÊNCIAS}

BELTRÃO, N.E.M. et al. Herbicidas diuron e pendimethalin na cultura da mamona, cultivo solteiro, no sudoeste da Bahia. In: CONGRESSO BRASILEIRO DE MAMONA, 1., 2004, Campina Grande. Energia e sustentabilidade. Anais... Campina Grande: Embrapa Algodão, 2004. 
EDMOND, J.B.; DRAPALA, W.S. The effects of temperature, sand and acetone on germination of okra seed. Proceedings of the American Society for Horticultural Science... New York, v.71, p.428-434, 1958.

FERREIRA, U.C. de Q.; QUEIROZ, W.N. de; BELTÃO, N.E. de M. Fitotoxicidade e seletividade do herbicida trifloxysulfuron sodium na mamona cultivar BRS Nordestina. Revista Brasileira de Engenharia Agrícola e Ambiental, v.13, p.916-921, 2009.

GELMINI, G. A. Herbicidas: indicações básicas. Campinas: CATI, 1985. 251p. (Documento Técnico, 52).

LIMA, M. G. de S. et al. Caracterização da qualidade fisiológica de sementes de mamona cultivar Guarani. Revista Brasileira de Biociências, v. 5, p.675-677, 2007.

MACIEL, C.D.G. et al. Seletividade de herbicidas em cultivares de mamona. Revista Brasileira de Oleaginosas e Fibrosas, v. 11, p. 47-54, 2007.

MAPA: Ministério da Agricultura, Pecuária e Abastecimento. Agrofit. Disponível em: http://extranet.agricultura.gov.br/agrofit_cons/principal_agrofit_cons Acesso em: 8 set. 2010

MARTINS, D. et al. Emergência em campo de dicotiledôneas infestantes em solo coberto com palha de cana-de-açúcar. Planta Daninha, v.17, p.151-161, 1999.

MARTINS, F. M. et al. Seletividade de herbicidas graminicidas aplicados em pós-emergência na cultura da mamona. In: CONGRESSO BRASILEIRO DA CIÊNCIA DAS PLANTAS DANINHAS, 24. 2004. São Pedro. Anais... Londrina: Sociedade Brasileira da Ciência das Plantas Daninhas, 2004. CD-ROM.

MEROTTO JÚNIOR., A.; VIDAL, R. A.; FLECK, N. G. Tolerância da cultivar de soja Coodetec 201 aos herbicidas Inibidores de ALS. Planta Daninha, v.18, p.93-102, 2000.

RAMIA, V. V. et al. Manejo Químico de Ricinus communis utilizando herbicidas seletivos à cana-de-açúcar. STAB, Açúcar, Álcool e Subprodutos, v.28, p.38-41, 2009.

THEISEN, G.; ANDRES, A. Manejo de plantas daninhas. In: SILVA, S.D. dos A. e; CASAGRANDE JUNIOR, J.G.; SCIVITTARO, W.B. A cultura da mamona no Rio Grande do Sul. Pelotas: Embrapa Clima Temperado, 2007. p.75-80.

THEISEN, G.; ANDRES, A.; SILVA, S. dos A. Seletividade de herbicidas à cultura da mamona. In: CONGRESSO BRASILEIRO DE MAMONA, 2., 2006. Anais... Campina Grande: Embrapa Algodão, 2005, 1 CD-ROM.

WEISS, E. Oilseed Crops, Tropical Agriculture Series. Longman Scientific and Technical, London, 1983, p.530-564.

ZOBIOLE, L.H.S. et al. Efeito da compactação do solo e do sulfentrazone sobre a cultura da soja em duas condições de água no solo. Planta daninha, v.25, p. 537-545, 2007. 